Elsevier required licence: (C) <2018>. This manuscript version is made available under the CC-BY-NC-ND 4.0 license http://creativecommons.org/licenses/by-nc-nd/4.0/ 


\title{
Effect of hydraulic retention time on the performance of a hybrid moving bed biofilm reactor-membrane bioreactor system for micropollutants removal from municipal wastewater
}

\author{
Qi Jiang ${ }^{\mathrm{a}}$, Hao H. Ngo ${ }^{\mathrm{a}}$, Long D. Nghiem ${ }^{\mathrm{b}}$, Faisal I. Hai ${ }^{\mathrm{b}}$, William E. Price ${ }^{\mathrm{c}}$, Jian Zhang ${ }^{\mathrm{d}}$, \\ Shuang Liang ${ }^{\mathrm{d}}$, Lijuan Deng ${ }^{\mathrm{a}, \mathrm{e}, \mathrm{f}}$, Wenshan Guo ${ }^{\mathrm{a}^{*}}$ \\ ${ }^{a}$ Centre for Technology in Water and Wastewater, School of Civil and Environmental Engineering, \\ University of Technology Sydney, Sydney, NSW 2007, Australia \\ ${ }^{b}$ Strategic Water Infrastructure Laboratory, School of Civil, Mining and Environmental \\ Engineering, University of Wollongong, Wollongong, NSW 2522, Australia \\ ${ }^{c}$ Strategic Water Infrastructure Laboratory, School of Chemistry, University of Wollongong, \\ Wollongong, NSW 2522, Australia \\ ${ }^{d}$ Shandong Provincial Key Laboratory of Water Pollution Control and Resource Reuse, School of \\ Environmental Science and Engineering, Shandong University, Jinan 250100, China \\ ${ }^{e}$ State Key Laboratory of Separation Membranes and Membrane Processes, Tianjin Polytechnic \\ University, Tianjin 300387, China \\ ${ }^{f}$ School of Environmental and Chemical Engineering, Tianjin Polytechnic University, Tianjin \\ 300387, China \\ * Corresponding author: Email: wguo@uts.edu.au, Tel: +61 (2) 95142739, Fax: + 61(2) 95147803
}

\begin{abstract}
This study evaluated micropollutants removal and membrane fouling behaviour of a hybrid moving bed biofilm reactor-membrane bioreactor (MBBR-MBR) system under four different hydraulic retention times (HRTs) $(24,18,12$ and $6 \mathrm{~h}$ ). The results revealed that HRT of $18 \mathrm{~h}$ was the optimal condition regarding the removal of most selected micropollutants. As the primary removal mechanism in the hybrid system was biodegradation, the attached growth pattern was desirable for enriching slowing growing bacteria and developing a diversity of biocoenosis. Thus, the efficient removal of micropollutants was obtained. In terms of membrane fouling propensity analysis, a longer HRT (e.g. HRTs of 24 and $18 \mathrm{~h}$ ) could significantly mitigate membrane fouling when
\end{abstract}


compared with the shortest HRT of $6 \mathrm{~h}$. Hence, enhanced system performance could be achieved when the MBBR-MBR system operated under HRT of $18 \mathrm{~h}$.

Keywords: Micropollutants removal; Moving bed biofilm reactor; Membrane bioreactor; Hydraulic retention time (HRT); Sponge

\section{Introduction}

Although the frequently detected micropollutants are at trace concentrations in our aquatic environment, they may cause long-term adverse effects, such as bioaccumulation and carcinogenicity (Klavarioti et al., 2009; Soares et al., 2008). Membrane bioreactors (MBRs), as a promising biological treatment technology, have been widely used to remove micropollutants (Tadkaew et al., 2011; Trinh et al., 2012; Wijekoon et al., 2013). However, two major concerns remain during the application of MBR systems, including membrane fouling, which could be alleviated by frequent physical and/or chemical backwashing or relaxation, and inconsistent removal of some polar and persistent hydrophilic micropollutants even at long hydraulic retention time (HRT).

Combination of moving bed biofilm reactor (MBBR) with MBR in series (MBBR-MBR) is one of recent advances in improving MBR performance, due to its potential for reducing membrane fouling and prolonging filtration duration as well as the possibility of prompting microbial degradation of certain organic compounds (Luo et al., 2015; Sombatsompop et al., 2006). It has been shown that the prolonged HRT decreased membrane fouling propensity and enhanced the formation of a diverse biocoenosis and biodegradation efficiency for certain micropollutants (De Gusseme et al., 2009; Schröder et 
al., 2012). Nevertheless, a previous research (Chen et al., 2008) concluded that the changes in HRT (HRTs of 8, 6, and $4 \mathrm{~h}$ ) had little effect on removal efficiency of Bisphenol A in a lab-scale submerged MBR, probably due to its rapid biodegradation and low potential for bioaccumulation.

Up to now, there has been no comprehensive study regarding the impact of HRT on micropollutants removal. Our previous investigation indicated that MBBR as pretreatment to MBR exhibited better performance in removing micropollutants than single conventional MBR (CMBR), and more importantly MBBR could mitigate membrane fouling of MBR to a great extent (Luo et al., 2015). Therefore, in this study, the performance of MBBR-MBR hybrid system was investigated at four different HRTs ( $24 \mathrm{~h}, 18 \mathrm{~h}, 12 \mathrm{~h}$, and $6 \mathrm{~h})$ to determine the optimal HRT in terms of micropollutants removal and membrane fouling control. Soluble microbial products (SMP), extracellular polymeric substances (EPS), zeta potential, and relative hydrophobicity $(\mathrm{RH})$ were used to examine the membrane fouling propensity.

\section{Materials and methods}

In this study, a set of 22 frequently detected micropollutants were selected to represent 11 pharmaceutical and personal care products (ibuprofen, acetaminophen, naproxen, ketoprofen, diclofenac, primidone, carbamazepine, salicylic acid, metronidazole, gemifibrozil and triclosan), 5 steroid hormones (estrone, 17- $\beta$-estradiol, $\beta$-estradiol 17-acetate, 17- $\alpha$ ethinylestradiol and estriol), 4 industrial chemicals (4-tert-butylphenol, bisphenol A, 4-tert-octylphenol and 4-n-nonylphenol) and 2 pesticides (fenoprop and pentachloro-phenol). The preparation of synthetic wastewater (containing micropollutants), 
characteristics of sponge carrier and analysis methods (e.g. concentrations of mixed liquor suspended solids (MLSS) and mixed liquor volatile suspended solids (MLVSS)) could refer to our previous study (Luo et al., 2014 and 2015). Influent and effluent samples were taken for analyses of dissolved organic carbon (DOC), chemical oxygen demand (COD), ammonium nitrogen $\left(\mathrm{NH}_{4}-\mathrm{N}\right)$, nitrate $\left(\mathrm{NO}_{3}-\mathrm{N}\right)$, nitrite $\left(\mathrm{NO}_{2}-\mathrm{N}\right)$, and orthophosphate $\left(\mathrm{PO}_{4}-\mathrm{P}\right)$. The hybrid MBBR-MBR system was composed of a $40 \mathrm{~L}$ MBBR unit and a $10 \mathrm{~L}$ submerged MBR unit. Four different HRTs of $24 \mathrm{~h}, 18 \mathrm{~h}, 12 \mathrm{~h}$ and $6 \mathrm{~h}$ were applied to the operation of MBBR unit, and the HRT of the MBR unit was kept at $6 \mathrm{~h}$ (i.e. constant flux of $8.33 \mathrm{~L} / \mathrm{m}^{2} \cdot \mathrm{h}$ ) throughout the experimental period. The filling ratio of sponge cubes in the MBBR unit was $20 \%$ ( $\left.\mathrm{v}_{\text {sponge }} / \mathrm{v}_{\text {reactor }}\right)$. For MBR unit, a hydrophilic polyvinylidene fluoride (PVDF) hollow fibre microfiltration (MF) membrane module was used with a pore size of $0.2 \mu \mathrm{m}$ and surface area of $0.2 \mathrm{~m}^{2}$. The operation conditions of the MBR unit were described in previous study by Luo et al. (2014). Chemical cleaning and fouling resistance analyses were performed when transmembrane pressure (TMP) reached $35 \mathrm{kPa}$ (Deng et al., 2014). Measurements of zeta potential, RH, particle size, EPS and SMP were carried out on sludge samples which were directly collected from the MBR unit. The analytical methods and the process for determining micropollutant concentration using solid phase extraction (SPE) and gas chromatography - mass spectrometry (GC-MS) quantification were reported in Luo et al. (2014).

\section{Results and Discussion}

3.1. The performance of MBBR at different HRTs

\subsubsection{Overall removal of organic carbon and nutrients in MBBR unit}


At HRTs of 24, 18, 12 and $6 \mathrm{~h}$, the MBBR unit was able to achieve effective removals of DOC $(>94 \%), \mathrm{COD}(>94 \%)$ and $\mathrm{NH}_{4}-\mathrm{N}(>82 \%)$, but unstable total nitrogen $(\mathrm{T}-\mathrm{N})$ (45.2-72.3\%) and $\mathrm{PO}_{4}-\mathrm{P}$ elimination (26.4-49.9\%). It was noteworthy that the MBBR showed the highest performance efficiency for removing DOC, $\mathrm{COD}, \mathrm{NH}_{4}-\mathrm{N}, \mathrm{PO}_{4}-\mathrm{P}$ and T-N at HRT of $18 \mathrm{~h}$, which were $96.1 \pm 0.4 \%, 97.4 \pm 0.8 \%, 91.1 \pm 1.6 \%, 49.9 \pm 7.2 \%$, and $72.3 \pm 6.9 \%$, respectively. This could be explained by the food to microorganisms $(\mathrm{F} / \mathrm{M})$ ratio in the MBBR unit. The F/M ratios were $0.72,1.83$, and $3.06 \mathrm{gCOD} / \mathrm{g} \mathrm{MLVSS} \cdot \mathrm{d}$ at HRTs of 24, 12 and $6 \mathrm{~h}$, respectively, while at HRT of $18 \mathrm{~h}$, the feed supplied for microorganisms was adequate for their growth with F/M ratio of $0.91 \mathrm{~g} \mathrm{COD/g} \mathrm{MLVSS} \cdot \mathrm{d}$, which was very close to the value (1.05 $\mathrm{g}$ COD/g VSS $\mathrm{d})$ as mentioned by Pozo et al. (2012) when treating kraft mill wastewater using a MBBR. The increased population of ammonium oxidation bacteria and utilization of phosphate by microorganisms for their growth and phosphorus uptake by phosphate accumulating organisms (PAOs) could contribute to high $\mathrm{NH}_{4}-\mathrm{N}$ and $\mathrm{PO}_{4}-\mathrm{P}$ removals at $\mathrm{HRT}$ of $18 \mathrm{~h}$, respectively. In the MBBR unit, MLSS concentrations maintained at very low levels $(0.13 \pm 0.05,0.09 \pm 0.02,0.11 \pm$ 0.02 and $0.13 \pm 0.02 \mathrm{~g} / \mathrm{L}$ at HRTs of $24,18,12$ and $6 \mathrm{~h}$, respectively). The attached biomass concentrations were $0.41 \pm 0.06 \mathrm{gMLVSS} / \mathrm{g}$ sponge (HRT of $24 \mathrm{~h}$ ), $0.47 \pm 0.03$ gMLVSS/g sponge (HRT of $18 \mathrm{~h}$ ), $0.40 \pm 0.03 \mathrm{gMLVSS} / \mathrm{g}$ sponge (HRT of $12 \mathrm{~h}$ ) and 0.37

$\pm 0.03 \mathrm{gMLVSS} / \mathrm{g}$ sponge (HRT of $6 \mathrm{~h}$ ), respectively.

\subsubsection{Removal and fate of the selected micropollutants in MBBR unit}

Significant variations on micropollutants removal among each individual compound were observed over the study period (Fig. 1). At HRT of $18 \mathrm{~h}$, the removals of most 
micropollutants remained constantly high over the experimental period except for carbamazepine, fenoprop, and metronidazole, because these three compounds are more recalcitrant due to the possession of electron withdrawing groups such as amide $\left(\mathrm{CONH}_{2}\right)$ carboxylic acid $(\mathrm{COOH})$ and nitro groups $\left(\mathrm{NO}_{2}\right)$. Particularly, the removal of diclofenac increased by at least $30 \%$ along with better removals of ketoprofen, gemifibrozil, acetaminiphen, bisphenol A, and pentachlorophenol as compared with those at other HRTs. Overall, the highest removal of most micropollutants could be accomplished at HRT of 18 h. The selected pharmaceutical and personal care products (PPCPs) in this study were mainly removed by biodegradation since they possessed low hydrophobicity (solid-water distribution coefficient, $\log \mathrm{D}<2.5)$ and their removal efficiencies were notably influenced by their intrinsic biodegradability (Luo et al., 2014; Tadkaew et al., 2011). The MBBR systems at all HRTs could effectively remove four of the investigated PPCPs, including ibuprofen (>92\%), salicylic acid (>90\%), primidone (> $81 \%)$, triclosan $(>80 \%)$, while carbamazepine showed particularly low removals $(<27 \%)$. Especially at HRT of $18 \mathrm{~h}$, the highest efficiencies of ibuprofen $(98.4 \pm 1.2 \%)$, salicylic acid $(98.1 \pm 0.5 \%)$, primidone $(90.9 \pm 1.2 \%)$, carbamazepine $(26.2 \pm 5.7 \%)$ and relatively higher triclosan removal efficiencies $(90.6 \pm 1.0 \%)$ were achieved. Additionally, a significant increase was observed in the removals of metronidazole and diclofenac from $27.4 \pm 10.8 \%$ and $33.3 \pm 11.0 \%$ (HRT of 24 h) to $50.8 \pm 6.5 \%$ and $83.3 \pm 7.8 \%$ (HRT of 18 h), respectively. Ketoprofen, acetaminophen, gemifibrozil, and naproxen were moderately removed (50-80\%) in MBBRs at all HRTs, but again achieved relatively higher removals (80-90\%) at HRT of 18 h. The observed removals for steroid hormones (estrone, estriol, $\beta$-estradiol 17-acetate, and 17ß-estradiol) and industrial chemicals (bisphenol A and 4-n-nonylphenol) were generally 
high (> 70\%) at all HRTs due to the high hydrophobicity of these compounds (except estriol). Regarding two pesticides, fenoprop exhibited inefficient elimination (16.5-50.5\%) owing to its low hydrophobicity $(\log \mathrm{D}=-0.13)$ and recalcitrance, whereas pentachlorophenol experienced much higher removals (71.3-92.8\%).

\section{Fig. 1.}

The equations used to evaluate the fate of micropollutants in the MBBR unit could refer to our previous study by Luo et al. (2015). It is noted that biodegradation was the main pathway for the removal of most micropollutants in the MBBR. At the prolonged HRT of $18 \mathrm{~h}$, major compounds of pharmaceuticals (especially salicylic acid, acetaminophen, naproxen, gemifibrozil, promidone, and ibuprofen), steroid hormones (except 17a-ethinylestradiol), industrial chemicals (biophenol A and 4-n-nonylphenol) and pesticides (pentachlorophenol) were mainly removed by biodegradation (> 80\%) (Fig. 2). Sorption accounted for much less proportion of most micropollutants removal when compared to biodegradation since sorption is a faster process. Moreover, sorption of micropollutants onto biosolids may prolong longer residence time, prompting further removal via biodegradation (Tadkaew et al., 2011). In addition, biomass could fully occupy the acclimatized sponge over time, which reduced the sorption site and sorption efficiency (Luo et al., 2014). As a result, although most micropollutants were effectively removed at HRT of $18 \mathrm{~h}$, the decreased sorption of $17 \alpha$-ethinylestradiol, triclosan and 4-tert-octylphenol was observed. When HRT was shortened to $6 \mathrm{~h}$, the biodegradation proportion declined, particularly for removals of acetaminophen, naproxen, gemifibrozil, pentachlorophenol, and biophenol A $(<75 \%)$. Although the proportion of sorption varied at different HRTs, it is notable that the percentage of sorption increased after HRT was 
changed to $6 \mathrm{~h}$, especially for removals of some highly hydrophobic compounds (4-tert-ocytlphenol, triclosan) and some persistent compounds (fenprop, carbamazepine).

Fig. 2.

3.2. Removal of organic carbon, nutrient and the selected micropollutants of $M B B R-M B R$ hybrid system

The MBBR-MBR system was able to achieve effective removals of DOC (94.7-96.7\%), COD (95.0-98.1\%) and $\mathrm{NH}_{4}-\mathrm{N}(83.1-92.1 \%)$, but low $\mathrm{PO}_{4}-\mathrm{P}(32.5-51.7 \%)$ and TN reductions (46.8-68.7\%). The initial MLSS and MLVSS in the MBR unit were similar to the concentrations of MLSS and MLVSS in MBBR tank, which gradually increased to 0.91 and $0.89 \mathrm{~g} / \mathrm{L}(\mathrm{HRT}$ of $24 \mathrm{~h}$ ), 1.02 and $0.98 \mathrm{~g} / \mathrm{L}$ (HRT of $18 \mathrm{~h}$ ), 1.09 and $1.04 \mathrm{~g} / \mathrm{L}(\mathrm{HRT}$ of $12 \mathrm{~h}$ ), and 1.05 and $0.96 \mathrm{~g} / \mathrm{L}$ (HRT of $6 \mathrm{~h}$ ) at the end of the experiment, respectively.

During the MBBR-MBR treatment, even the micropollutants removal varied significantly $(11.0 \%-99.5 \%)$, most compounds were eliminated to large extents $(>70 \%)$ as the attached growth pattern provided a desirable environment for slow growing bacteria and facilitated a diverse biocoenosis. On one hand, the removal of micropollutants by MBR was limited due to low MLSS concentration and the utilization of $0.2 \mu \mathrm{m}$ pore size MF membrane (Luo et al., 2015). On the other hand, both metronidazole and carbamazepine are nitrogen bearing compounds, and the enhanced removal could be the result of the infinte sludge retention time (SRT) applied in the MBR unit. Additionally, compounds like gemfibrozil, pentachlorophenol and diclofenac were most likely to be removed by biodegradation rather than by MF filtration. As to the fate of micropollutants removal in the 
MBBR-MBR, noting that the hydrophobic compounds were mostly detected at low concentration in biosolids at all HRTs, while some persistent hydrophilic compounds (e.g. carbamazepine) consistently presented very high solid phase concentration.

\subsection{Membrane fouling analysis in MBR unit}

Fig. 3 depicts the time course of TMP increase in the MBR unit. The TMP in the MBR unit reached up to $35 \mathrm{kPa}, 36.5 \mathrm{kPa}, 37.5 \mathrm{kPa}$ and $36.5 \mathrm{kPa}$ in 89 days, 74 days, 42 days and 20 days of operation at HRTs of $24,18,12$, and $6 \mathrm{~h}$, corresponding to fouling rates of $0.39 \mathrm{kPa} / \mathrm{d}, 0.49 \mathrm{kPa} / \mathrm{d}, 0.89 \mathrm{kPa} / \mathrm{d}$, and $1.83 \mathrm{kPa} / \mathrm{d}$, respectively. Therefore, a longer HRT (e.g. HRT of $24 \mathrm{~h}$ ) could significantly mitigate membrane fouling when compared with a relatively short HRT (e.g. HRT of 6 h). Especially, the TMP value maintained less than $15 \mathrm{kPa}$ for 60 days (HRT of $18 \mathrm{~h}$ ) and 68 days (HRT of $24 \mathrm{~h}$ ) of operation. Total fouling resistances $\left(\mathrm{R}_{\mathrm{T}}\right)$ were $12.59 \times 10^{12}, 12.08 \times 10^{12}, 11.55 \times 10^{12}$ and $11.28 \times 10^{12} \mathrm{~m}^{-1}$ at the end of experiments under HRTs of $24,18,12$ and $6 \mathrm{~h}$, respectively. The cake resistance $\left(\mathrm{R}_{\mathrm{C}}\right)$ consisted of about $70 \%$ of $\mathrm{R}_{\mathrm{T}}$ at all $\mathrm{HRTs}$, indicating that the main contributor to membrane fouling was formation of cake layer. Pore blocking resistance $\left(\mathrm{R}_{\mathrm{P}}\right)$ was higher at shorter HRT of $6 \mathrm{~h}\left(1.92 \times 10^{12} \mathrm{~m}^{-1}, 12.0 \%\right.$ of $\left.\mathrm{R}_{\mathrm{T}}\right)$ than that at longer HRT of $24 \mathrm{~h}\left(1.51 \times 10^{12} \mathrm{~m}^{-1}, 17.0 \%\right.$ of $\left.\mathrm{R}_{\mathrm{T}}\right)$ and $18 \mathrm{~h}\left(1.90 \times 10^{12} \mathrm{~m}^{-1}, 15.7 \%\right.$ of $\left.\mathrm{R}_{\mathrm{T}}\right)$. The zeta potential increased while RH decreased when the HRT was changed from $24 \mathrm{~h}(-15.6 \pm 3.5$ $\mathrm{mV}$ and $79.2 \pm 4.2 \%$, respectively) to $18 \mathrm{~h}(-15.7 \pm 3.9 \mathrm{mV}$ and $77.0 \pm 4.0 \%$, respectively) and further $6 \mathrm{~h}(-19.5 \pm 1.4 \mathrm{mV}$ and $72.0 \pm 3.6 \%$, respectively). Hydrophobic sludge flocs (high RH value) enhanced flocculation and limited their interaction with the hydrophilic membrane. The decline in negative charge on sludge floc surface due to the increased zeta 
potential could prompt the aggregation of flocs by charge neutralization mechanism, resulting in formation of larger flocs at longer HRTs of 24 and $18 \mathrm{~h}(15-40 \mu \mathrm{m})$ than those at HRT of $6 \mathrm{~h}(10-25 \mu \mathrm{m})$ (Ji et al., 2010). Thus, less fouling was observed at longer HRTs. As shown in Fig. 4, the levels of EPS were similar at the beginning of all HRTs, and then gradually increased to $15.24 \mathrm{mg} / \mathrm{L}, 16.43 \mathrm{mg} / \mathrm{L}, 19.88 \mathrm{mg} / \mathrm{L}$ and $22.93 \mathrm{mg} / \mathrm{L}$ at the end of operation at HRTs of $24 \mathrm{~h}, 18 \mathrm{~h}, 12 \mathrm{~h}$, and $6 \mathrm{~h}$, respectively. The SMP concentration varied for different HRTs but showed minor variation under the same HRT. SMP concentrations were lower at HRTs of 24 and $18 \mathrm{~h}$ (4.89-6.32 and 4.93-9.96 mg/L, respectively), whereas signficantly higher SMP concentations were observed at HRT of $6 \mathrm{~h}$ in the range of $16.60-29.68 \mathrm{mg} / \mathrm{L}$. Thus, the accumulation of SMP and EPS at shorter HRT aggravated membrane fouling (Guo et al., 2012).

Fig. 3.

Fig. 4.

\section{Conclusion}

In this study, at 4 different HRTs was investigated in terms of micropollutants removal and fouling control. The MBBR appeared to be an effective process for removing most of the selected micropollutants at all HRTs. At HRT of $18 \mathrm{~h}$, the MBBR-MBR system was not only able to achieve comparable organic and nutrient removal, but also improve the removal of micropollutants compared to other biological treatment processes (i.e. activated sludge and MBR) and prolong the operative time due to efficient fouling reduction.

\section{Supplementary information}


Properties of the selected micropollutants, comparison of micropollutants removal in MBBR-MBR and in other biological treatment processes (activated sludge and MBR), as well as the fate of the studied micropollutants in the MBBR unit at HRTs of 24, 12, $6 \mathrm{~h}$ can be found in supplementary information.

\section{References}

1. Chen, J., Huang, X., Lee, D., 2008. Bisphenol A removal by a membrane bioreactor. Process Biochem. 43, 451-456.

2. De Gusseme, B., Pycke, B., Hennebel, T., Marcoen, A., Vlaeminck, S.E., Noppe, H., Boon N., Verstraete, W., 2009. Biological removal of 17a-ethinylestradiol by a nitrifier enrichment culture in a membrane bioreactor. Water Res. 43, 2493-2503.

3. Deng, L., Guo, W., Ngo, H.H., Zhang, J., Liang, S., Xia, S., Zhang, Z., Li, J., 2014. A comparison study on membrane fouling in a sponge-submerged membrane bioreactor and a conventional membrane bioreactor. Bioresour. Technol. 165, 69-74.

4. Guo, W., Ngo, H.H., Li, J., 2012. A mini-review on membrane fouling. Bioresour. Technol. 122, 27-34.

5. Ji, J., Qiu, J., Wai, N., Wong, F.S., Li, Y., 2010. Influence of organic and inorganic flocculants on physical-chemical properties of biomass and membrane-fouling rate. Water Res. 44, 1627-1635.

6. Klavarioti, M., Mantzavinos, D., Kassinos, D., 2009. Removal of residual pharmaceuticals from aqueous systems by advanced oxidation processes. Environment international 35, 402-417.

7. Luo, Y., Guo, W., Ngo, H.H., Nghiem, L.D., Hai, F.I., Kang, J., Xia, S., Zhang, Z., Price W.E., 2014. Removal and fate of micropollutants in a sponge-based moving bed bioreactor. Bioresour. Technol. 159, 311-319.

8. Luo, Y., Jiang, Q., Ngo, H.H., Nghiem, L.D., Hai, F.I., Price, W.E., Wang, J., Guo, W., 2015. Evaluation of micropollutant removal and fouling reduction in a hybrid moving bed biofilm reactor-membrane bioreactor system. Bioresour. Technol. 191, 355-359.

9. Pozo, G., Villamar, C.A., Martínez, M., Vidal, G., 2012. Effect of organic load and nutrient ratio on the operation stability of the moving bed bioreactor for kraft mill wastewater treatment and the incidence of polyhydroxyalkanoate biosynthesis. Water Sci. Technol. 66, 370-376. 
10. Schröder, H.F., Tambosi, J.L., Sena, R.F., Moreira, R.F.P.M., Jose, H.J., Pinnekamp, J. 2012. The removal and degradation of pharmaceutical compounds during membrane bioreactor treatment. Water Sci. Technol. 65, 833-839.

11. Soares, A., Guieysse, B., Jefferson, B., Cartmell, E., Lester, J.N., 2008. Nonylphenol in the environment: a critical review on occurrence, fate, toxicity and treatment in wastewaters. Environment international 34, 1033-1049.

12. Sombatsompop, K., Visvanathan, C., Aim, R.B., 2006. Evaluation of biofouling phenomenon in suspended and attached growth membrane bioreactor systems. Desalination 201, 138-149.

13. Tadkaew, N., Hai, F.I., McDonald, J.A., Khan, S.J., Nghiem, L.D., 2011. Removal of trace organics by MBR treatment: the role of molecular properties. Water Res. 45, 2439-2451.

14. Trinh, T., Van Den Akker, B., Stuetz, R.M., Coleman, H.M., Le-Clech, P., Khan, S.J., 2012. Removal of trace organic chemical contaminants by a membrane bioreactor. Water Sci. Technol. 66, 1856-1863.

15. Wijekoon, K.C., Hai, F.I., Kang, J., Price, W. E., Guo, W., Ngo, H.H., Nghiem, L.D., 2013. The fate of pharmaceuticals, steroid hormones, phytoestrogens, UV-filters and pesticides during MBR treatment. Bioresour. Technol. 144, 247-254. 


\section{Figure captions}

\section{Figure captions}

Fig. 1. Micropollutants removal in the MBBR unit at HRTs of $24 \mathrm{~h}, 18 \mathrm{~h}, 12 \mathrm{~h}$, and $6 \mathrm{~h}$. The error bar of each sample represents the standard deviation over the experiment period

Fig. 2. Fate of studied micropollutants in the MBBR unit at HRT of $18 \mathrm{~h}$

Fig. 3. Comparison of TMP profiles in the MBR when MBBR was operating at HRTs of $24 \mathrm{~h}, 18 \mathrm{~h}, 12 \mathrm{~h}$, and $6 \mathrm{~h}$

Fig. 4. Comparison of EPS and SMP values in the MBR when MBBR was operating at HRTs of $24 \mathrm{~h}, 18 \mathrm{~h}$, $12 \mathrm{~h}$, and $6 \mathrm{~h}$ 


\section{ACCEPTED MANUSCRIPT}

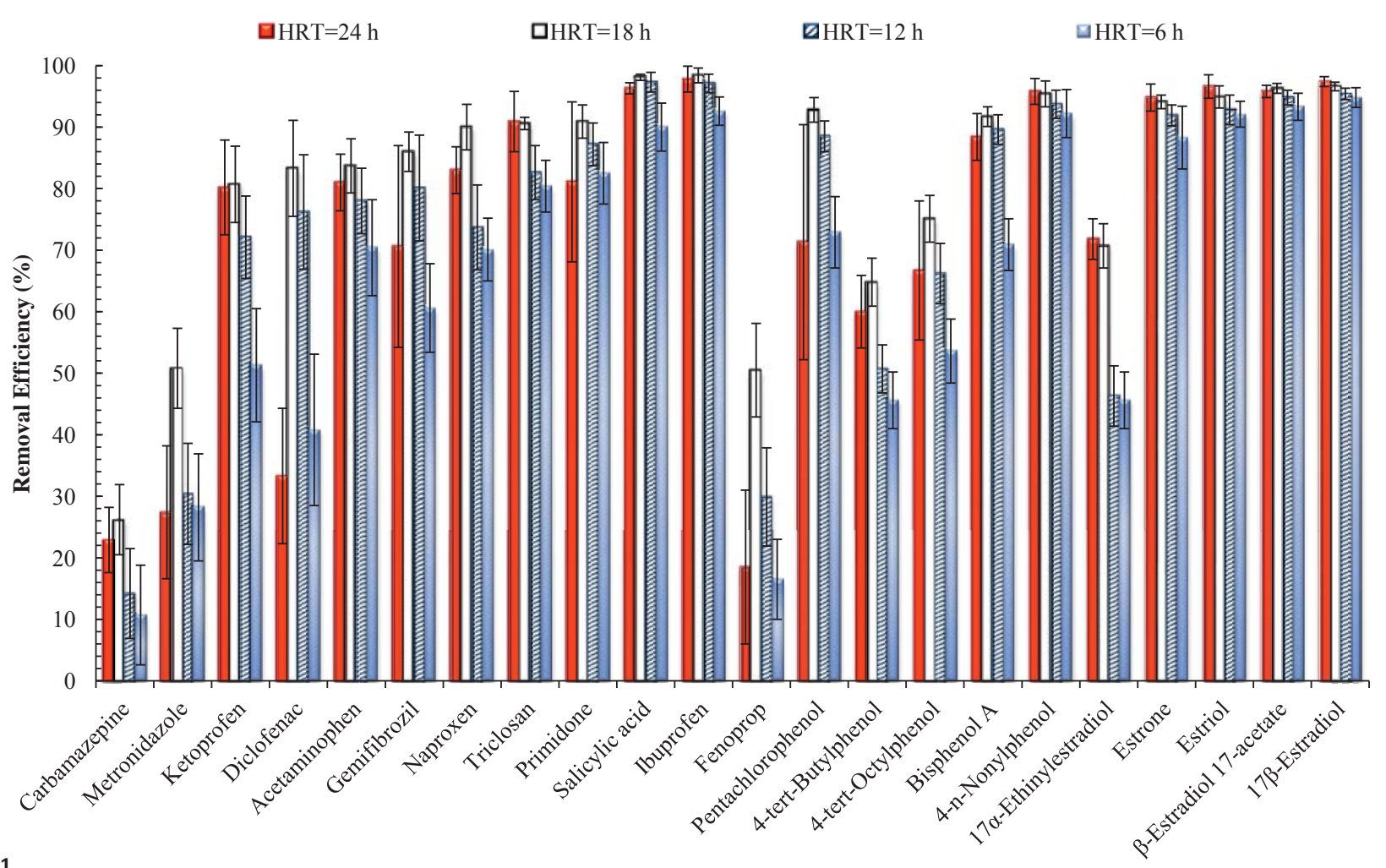

Fig. 1.

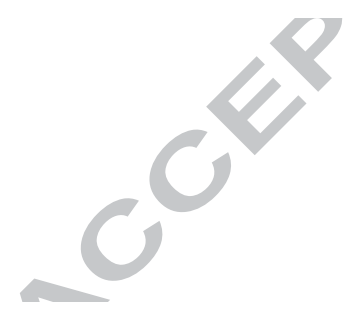




\section{ACCEPTED MANUSCRIPT}

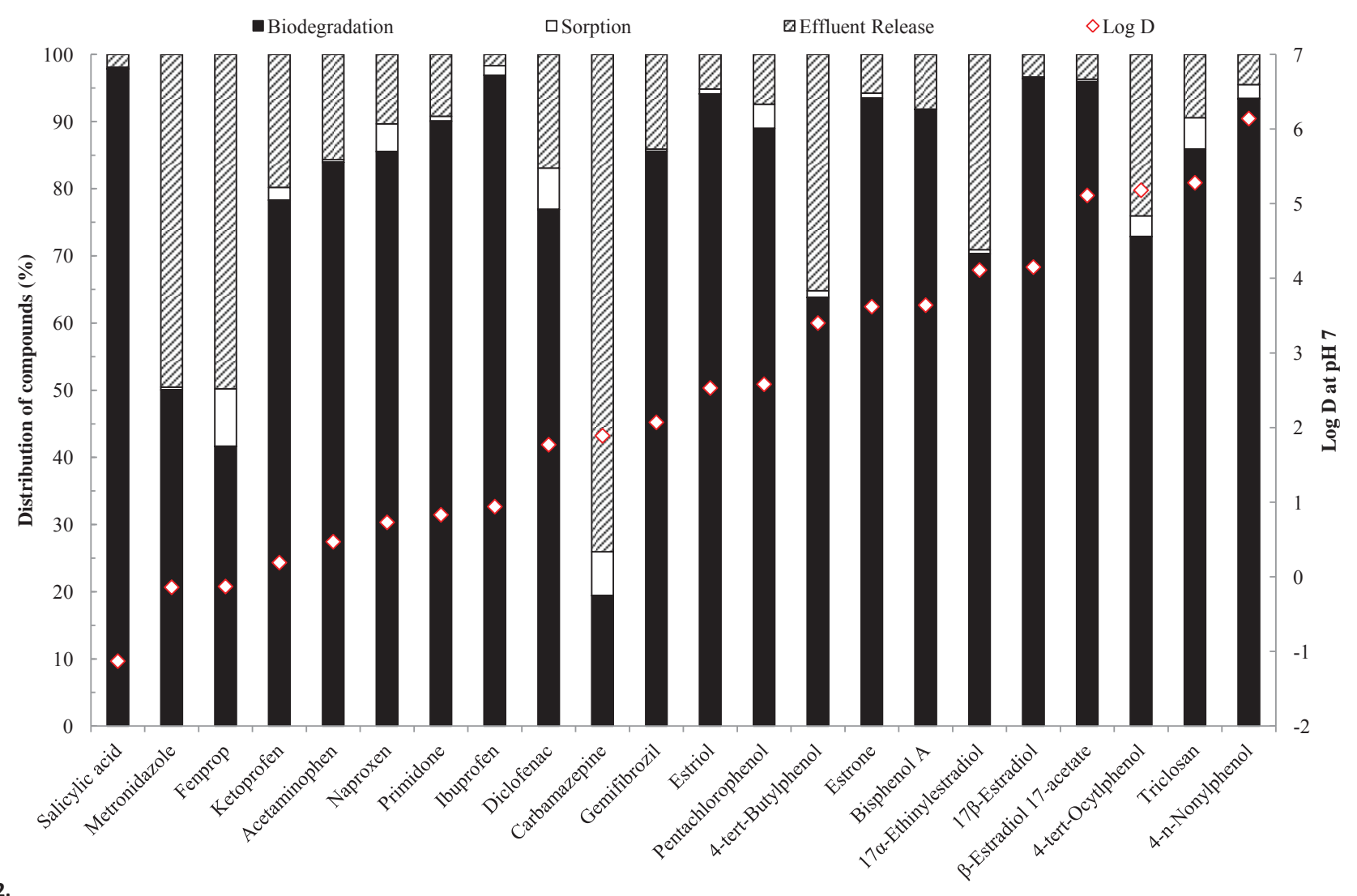

Fig. 2. 


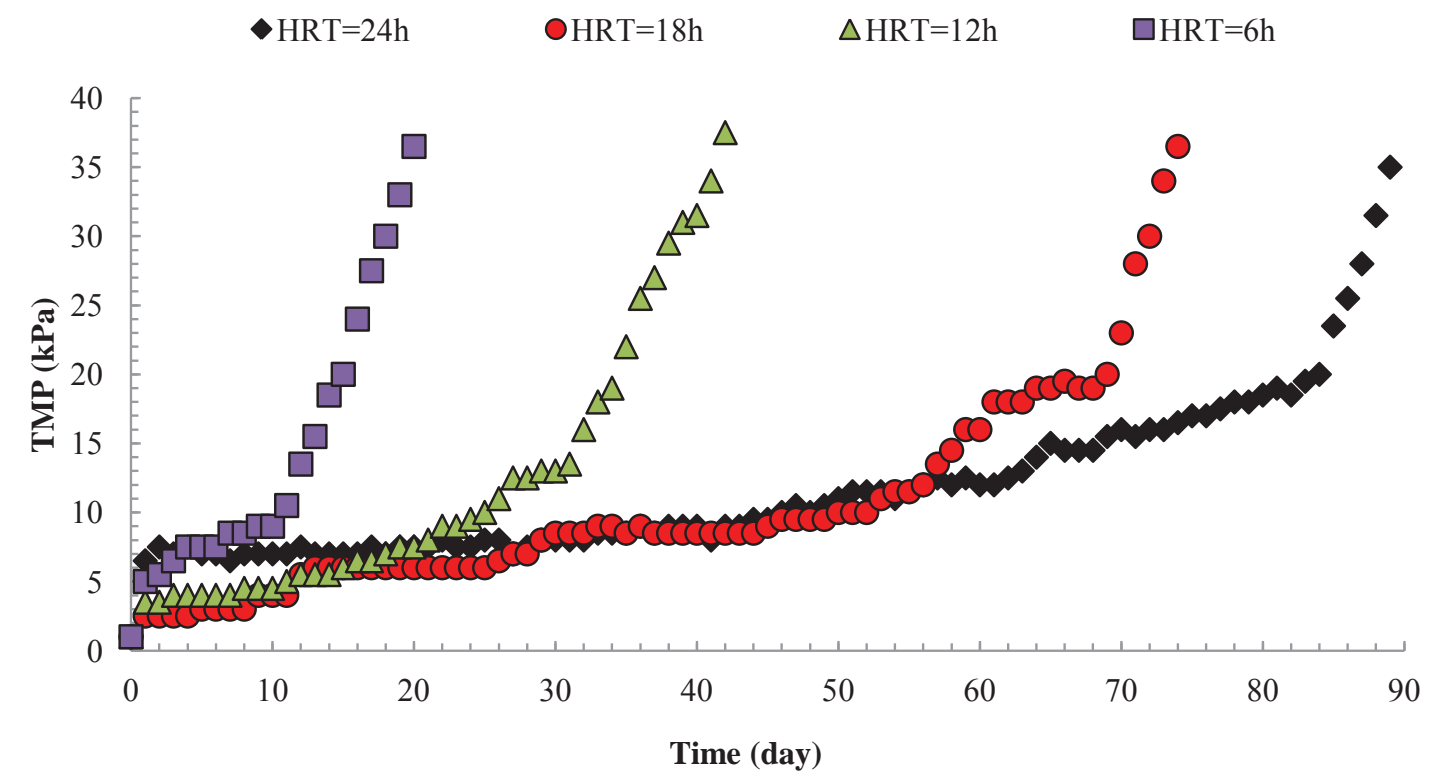

Fig. 3. 


\section{ACCEPTED MANUSCRIPT}

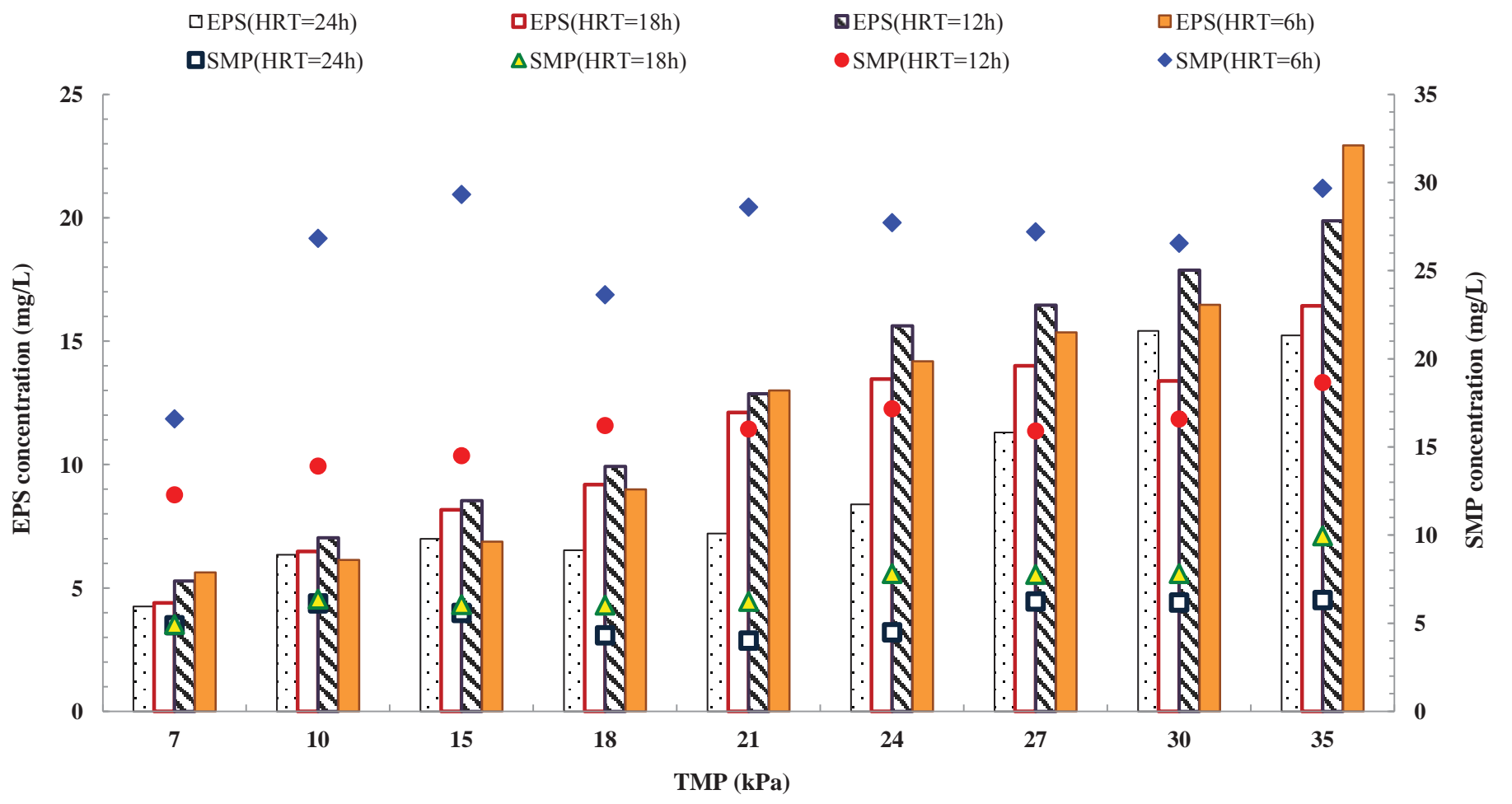

Fig. 4. 